Division of Dermatology and Departments of Medicine and Paediatrics, University of California School of Medicine, San Francisco, California

eoformans, that athogenicity of $k$ on this point.

bject. There is ed animals and nce mechanisms

tological level, parasitism.

Candida albicans.

(1) Observation

ne Antibiotics in

eatment. London:

J. Path. Bact.

albicans. Nature,

inn. Mo. bot. Gdn,

oc. Soc. exp. Biol.

Mouse Epithelial

fections, ed. H. I.

trop. Med. Hyg.,

, Paris: Masson,

uneous Moniliasis.

apter 3 .

pter 19.

col. appl., 35, 10 .

\section{BACTERIAL INTERFERENCE: RELATING TO CHRONIC FURUNCULOSIS IN MAN*}

\author{
HOWARD I. MAIBACH, WALTER G. STRAUSS,
} AND HENRY R. SHINEFIELD

FURUNCULOSIS is an annoying but generally benign infection. Most individuals have but 1 or 2 such boils and are free from subsequent lesions from years to life. Some individuals, however, have recurrent boils. We arbitrarily define recurrent furunculosis as multiple boils exceeding one year's duration. Most cases to which we refer here had boils for many years.

\section{NATURAL HISTORY OF FURUNCULOSIS}

Any physician claiming a cure for recurrent furunculosis must bear in mind their curious natural history. The definitive controlled study is that of Roodyn in the British Isles (Roodyn, 1960). He observed families over many years and demonstrated sporadic patterns of infections. He cultured and phage typed their boils. As seen in Fig. 1, one strain of staphylococci produced infection in this family intermittently over 6 years. The factors responsible for the general quiescence and only occasional presence of disease remain unknown for most infectious diseases. His data shows that if one relied on short term studies or inadequately controlled studies, one could easily claim therapeutic response where, in fact, the natural history only was being observed.

We previously examined the effect of staphylococcus toxoids in chronic furunculosis (Maibach and Kligman, 1962). We studied a population of four groups each of 150 mental defectives in a closed population. These groups had a past history of numerous episodes of furuncules each year. The vaccines studied were of 3 types; fortunately we utilized a placebo group. As demonstrated in Fig. 2, we might have been led to believe that a dramatic therapeutic result had occurred equally in the vaccine groups. The placebo group had a similar fortuitous response. These examples demonstrate the hazards of attempting to prove therapeutic response in furunculosis.

\section{BACTERIAL INTERFERENCE IN NEONATAL HOSPITAL INFECTION}

The impetus for our interest was the observations of Shinefield and his colleagues (Shinefield et al., 1966). They demonstrated that naturally occurring and artificially induced colonization of the nasal mucosa of adults and infants with a marker strain of staphylococci interferes with the subsequent acquisition of the sites by other strains of staphylococci. They called the phenomenon bacterial interference. They published considerable data demonstrating this technique as a method for terminating hospital infection and disease caused by hospital strains of Staphylococcus aureus (Boris, 1968).

Their attention had been drawn to this phenomenon by epidemiological data. A hospital nurse known to be a nasal carrier of $S$. aureus type $80 / 81$ had repeated contacts with 68 new born infants of various ages. Among the 37 babies handled by her during their first $24 \mathrm{~h}$. the colonization rate with $S$. aureus type $80 / 81$ was $22 \%$; of the 31 infants more than $24 \mathrm{~h}$. old cared for by the same nurse carrier during the identical time, none were similarly colonized. Detailed analysis indicated that $84 \%$ of the infants more

* Presented to the Third Course on Progress in the Biological Sciences in Relation to Dermatology, University of Cambridge, September 23rd-28th, 1968. 


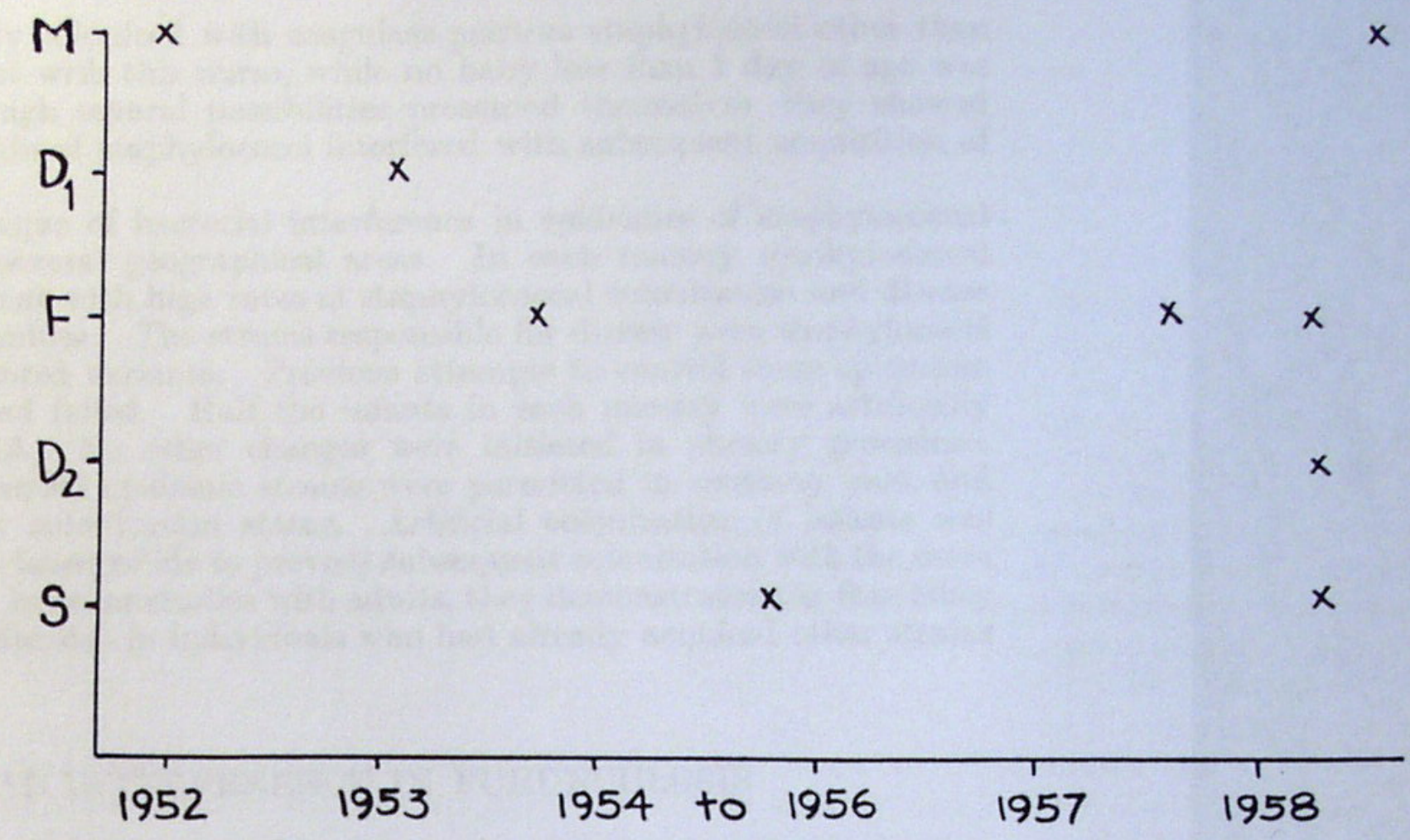

Fig. 1.-Natural history of recurrent furunculosis (adapted from Roodyn 1960). One strain of $S$. aureus was responsible for repeated infections for 6 years.

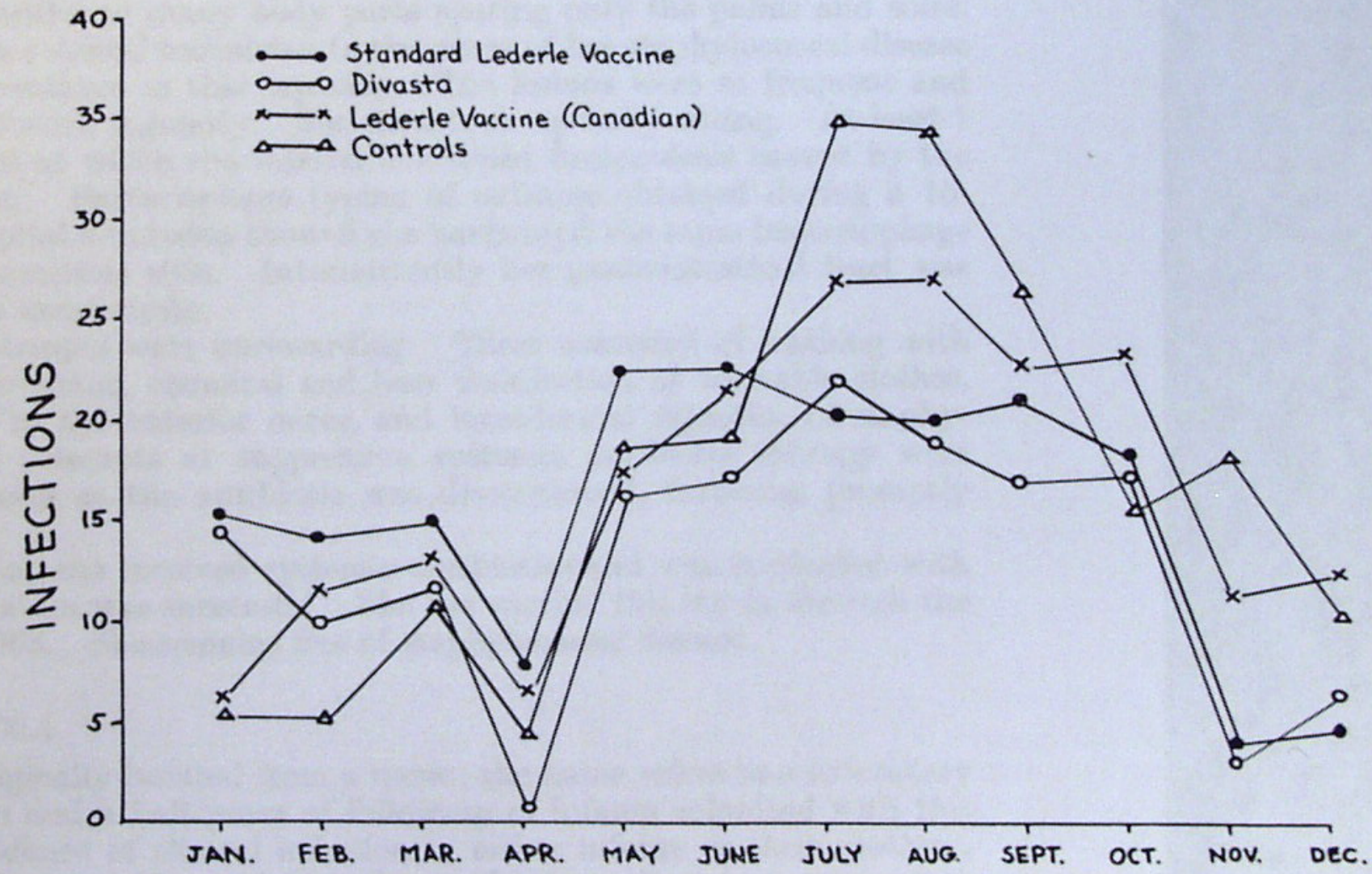

FIG. 2.- Staphylococcal toxoid therapy in recurrent furunculosis. The vertical axis lists numbers of infections and the horizontal axis the months. Note the dramatic increase of of infection in the warmer months and the decrease in the Autumn. Placebo results paralleled the treatment group results. 
than $24 \mathrm{~h}$. old were nasally colonized with coagulase-positive staphylococci other than type $80 / 81$ prior to contact with this nurse, while no baby less than 1 day of age was similarly infected. Although several possibilities presented themselves, they showed that the presence of 1 strain of staphylococci interfered with subsequent acquisition of another strain.

They utilized the technique of bacterial interference in epidemics of staphylococcal infection in nurseries in several geographical areas. In each nursery staphylococcal disease was currently present with high rates of staphylococcal colonization and disease in the infants and their families. The strains responsible for disease were staphylococci of phage type $80 / 81$ or related variants. Previous attempts to control these epidemics with standard methods had failed. Half the infants in each nursery were artificially colonized with strain 502A. No other changes were initiated in nursery procedure. Hospital personnel who carried epidemic strains were permitted to continue work and were not notified of their colonization status. Artificial colonization of infants was performed within the early hours of life to prevent subsequent colonization with the more virulent hospital strains. In other studies with adults, they demonstrated the feasibility of inducing bacterial interference in individuals who had already acquired other strains of staphylococci.

\section{BACTERIAL INTERFERENCE IN FURUNCULOSIS}

\section{Initial Experience}

Their experience encouraged us to treat our first patient with recurrent furunculosis (Strauss et al., 1965). This was a 43-year old housewife admitted to the University of California Hospital in December 1963 with recurring furuncles and carbuncles beginning at age 35 , shortly after hospitalization for accidental trauma. The infections occurred approximately every 2 months on many body parts sparing only the palms and soles. The patient had worked as a dental technician to the onset of her staphylococcal disease and then was unable to continue in this capacity. The lesions were so frequent and painful that she could not work regularly. She then took up baby-sitting. At least 1 child and 1 adult in homes at which she worked developed furunculosis caused by the same staphylococcal strain. Bacteriophage typing of cultures obtained during a 15month period prior to hospital admission showed she harboured the same bacteriophage type staphylococcus on numerous sites. Intermittently her gastrointestinal tract was heavily colonized with the same strain.

Previous therapeutic attempts were unrewarding. These consisted of washing with soap containing hexachlorophane, chemical and heat disinfection of washable clothes, application of antibiotics to the anterior nares, and intradermal injection of staphylococcus toxoid. Several attempts at suppressive systemic antibiotic therapy were successful; however, as soon as the antibiotic was discontinued, furuncles promptly occurred.

During the hospitalization she received systemic antibiotics and was implanted with strain $502 \mathrm{~A}$. The colonization was successful. She has carried this strain through the last examination in late 1968. She remains free of staphylococcal disease.

\section{Characteristics of Strain $502 \mathrm{~A}$}

The $502 \mathrm{~A}$ strain was originally isolated from a nurse; the name refers to a laboratory acquisition number. Two and a half years of follow-up of infants colonized with this strain failed to reveal evidence of clinical infection in either infants or their mothers.

The strain is sensitive to penicillin and high doses of tetracycline, but resistant to low doses of tetracycline. It is a Group $3 S$. aureus and bacteriophage type $6 / 7 / 42 \mathrm{D} /$ $42 \mathrm{~A} / 53 / 54 / 75 / 81$. The reason that this strain appears less pathogenic or virulent than some of the "hospital" staphylococci remains unexplained. Yet its disease producing 
capacities are clearly distinguishable from more virulent strains. Someday mechanisms for these differences will be understood; in the interim, we have preferred to use this strain rather than to seek to identify other less virulent strains. The mass of biological information now available on strain $502 \mathrm{~A}$ is such that it will be difficult to obtain equal information on other strains until we can do this on a logical rather than empirical basis.

\section{Double Blind Studies}

We have continued to do controlled studies in additional patients with recurrent furunculosis. However, Boris and his colleagues recently published the results of their controlled studies (Boris et al., 1968). Their data convincingly demonstrates that artificial colonization with strain $502 \mathrm{~A}$ not only protects families against recolonization by the original strain of $S$. aureus, but also significantly interrupts chronic familial staphy. lococcal disease. Their study groups were families in which more than 1 member had recurrent staphylococcal lesions for at least 1 year. All had received varied previous treatments including staphylococcal toxoids, antibiotics and antiseptic washes. If cultures of the nose and throat revealed a single strain in several of the family, they were qualified for admission into the studt. The families were randomly placed in the control or $572 \mathrm{~A}$ inoculated group. Prior to colonization, all received topical and systemic antibiotics.

Their groups were matched and divided into the control and treatment groups. This included resistance of their organisms to penicillin and the phage types of staphylococci. Their results were definitive. Of the 51 individuals treated in the control group, 15 individuals had infections in the first year after antibiotic treatment and saline inoculation. In the larger group of 82 in the 502A inoculated group, there were 4 infections. We believe this data is not only statistically but biologically of significance (Table I).

\section{TABLE I}

Type of lesion
Cutaneous abscesses
Impetigo
Pustule
Ischio-rectal abscesses
Otitis externa
Peritonitis
Styes
Total

\begin{tabular}{|c|c|}
\hline \multicolumn{2}{|c|}{ No. of Lesions } \\
\hline Control group & 502 A group \\
\hline 8 & - \\
\hline 5 & - \\
\hline 4 & 3 \\
\hline 3 & - \\
\hline 1 & - \\
\hline 1 & - \\
\hline 5 & 1 \\
\hline 27 & 4 \\
\hline
\end{tabular}

Infections found in controlled studies of Boris et al. (adapted from Boris et al., 1968). All subjects received topical and systemic antibiotics and differed only in saline inoculation versus 502 inocula. tion. Note the reduced incidence of infection in the first year in the $502 \mathrm{~A}$ treated group.

\section{Strain Relationships}

In our studies we have been impressed with the ability of the human body to discern the difference between 502A and other staphylococci. We have had several treatment failures which strongly suggest the relationship of strain to pathogenicity. Several examples follow:

A 20-year-old girl had multiple furuncles between June 1965 and 1966. Cultures of pus from furuncles grew; $S$. aureus phage type $3 \mathrm{~B} / 55 / 71$. Cultures of other sites did not yield $S$. aureus. She received antibiotics and was colonized with strain $502 \mathrm{~A}$ in September 1966. This new strain was cultured from multiple sites between October and January 1967. All sites were negative for coagulase-positive staphylococci in June 
1967. In December 1967, she had the first recurrent furuncle since 502A trunsplantation. The lesions in her nose were cultured and revealed her original strain but no strain $502 \mathrm{~A}$. Thus, she had 2 periods of furunculosis with a pathogenic strain separated by periods of several months during which she was free from furuncle and carried struin $502 \mathrm{~A}$ or no S. aureus.

A 10-year-old boy had numerous furuncles from 1962 to 1966 . Phago type 52A/79 was repeatedly cultured from these and clinically uninvolved skin. He received systemic antibiotics, was colonized with strain 502A in January 1967 and carried this for 6 months during which he was asymptomatic. He then had a stye from which phage type $52 \mathrm{~A} / 79$ was cultured. Nose and throat were positive for $52 \mathrm{~A} / 79$ but no $502 \mathrm{~A}$ was recovered. He had a furuncle of the upper lip in September 1967 from which 52A/79 was cultured. Again this patient had 2 episodes of furunculosis with his usual strain separated by a furuncle-free period during which he carried only strain 502A.

A common phenomenon occurred in these patients. Furuncles were associated only with carriage of their original strain of staphylococcus. During periods of $502 \mathrm{~A}$ carriage, these patients remained free of lesions. The sequence consisted of furuncles associated with the original strain, freedom from lesions while carrying $502 \mathrm{~A}$ and then relapse when $502 \mathrm{~A}$ was lost and replaced by the original pathogenic strain. This sequence provides additional evidence to establish that strain $502 \mathrm{~A}$ is less pathogenic on these hosts and can interrupt furunculosis. We have transplanted an additional 11 patients with $502 \mathrm{~A}$, with follow-up of at least $1 \frac{1}{2}$ years. Of these, 9 have retained $502 \mathrm{~A}$ and have no boils. One patient was successfully transplanted with 502A, ceased having furuncles and then had a strain relapse without developing new furuncles to date. Thess: observations provide additional support for the hypothesis that $502 \mathrm{~A}$ is less pathogenic for those hosts with recurrent furuncles.

\section{Risk of $502 \mathrm{~A}$ Induced Infections}

Our original efforts in this field were made with extreme caution becsuse of fear of producing disease with $502 \mathrm{~A}$ strain. In retrospect we believe our concerns exaggerated and somewhat unjustified. Drutz and his associates did, in fact, report a patient who developed abscesses in which 502A was isolated (Drutz et al., 1966). Their data is such that one cannot be certain if the original strain was also in the lesion. 'To date, there have been no serious infections caused in the several thousand infants and adults who have been colonized with $502 \mathrm{~A}$. Our personal experiences with furunculosis patients and other volunteers we have colonized, reveal no infections more serious than pustules. These pustules have occurred on skin where large numbers of $502 \mathrm{~A}$ were applied. They healed spontaneously and without therapy. We have personally not obscrved recurrent pustules or recurrent $502 \mathrm{~A}$ induced furuncles. However, with any organism, no matter how decreased its virulence, serious infection may occur. We believe the risks so minimal as to be justified when the indications for such therapy are present.

\section{Other Methods of Establishing Strain $502 \mathrm{~A}$ in a Host}

The above treatment failures suggest the requirement for improvexl methods of colonization with strain 502A. The variables involved are poorly urderstood. In some instances, in spite of seemingly appropriate topical and systemic antifiotic therapy, strain $502 \mathrm{~A}$ failed to maintain its numerical superiority over the resident strain. In other instances, individuals became colonized with $502 \mathrm{~A}$ without additional suppression of the resident flora with antibiotics. Table II shows data of such a family. When studied from September 1962 to November 1963, 3 sons in the family carried 52A/80. Their mother was colonized in November 1963. By August of 1964, 2 of the 3 sons and their father had spontaneously been colonized with strain $502 \mathrm{~A}$, presumably by contact with their mother or each other. Son 2 continued to carry his resident strain. Here 
TABLE II

September 1962

to November 1963 August 1964

$\begin{array}{lc}\text { Family member } & \text { Phage type } \\ \text { Son 1 } & \\ \text { Son 2 } & 52 / 52 \mathrm{~A} / 80 \\ \text { Son 3 } & \\ \text { Mother colonized with } 502 \mathrm{~A} \\ \text { Son 1 } & \text { "502A" } \\ \text { Son 3 } & \text { "502A" } \\ \text { Father } & 502 \mathrm{~A} " \\ \text { Son 2 } & 52 / 52 \mathrm{~A} / 80\end{array}$

Familial colonization. In this instance, the mother was colonized with strain $502 \mathrm{~A}$ and 2 or 3 sons subsequently lost their resident strain which was replaced with strain $502 \mathrm{~A}$.

was clearly an efficient method of colonizing with 502A. This is hardly a practical method in routine therapeutic circumstances, but provides a model which can hopefully be understood and imitated.

We have utilized other antibacterial substances in an effort to increase our successful colonization rate. One such agent is lysostaphin, an enzyme produced by a nonpigmented staphylococcus (Martin and White, 1967). This is a basic peptide of about 30,000 molecular weight which selectively lyses polyglycine bridges found in the cell walls of only $S$. aureus. Lysostaphin is highly active in vitro against coagulase positive staphylococci but has little activity against coagulase negative staphylococci or diphtheroids which are usually part of the nasal flora of man.

\section{TABLE III}

$\begin{array}{rc}\text { Subjects } \\ \text { "C " } 2 & \text { Pre-treatment } \\ & \mathrm{R} \\ 5 & \mathrm{R} \\ & \\ 8 & \mathrm{R} \\ 11 & \mathrm{R} \\ 12 & \mathrm{R} \\ 3 & \mathrm{R} \\ 4 & \mathrm{R} \\ 6 & \mathrm{R} \\ 7 & \mathrm{R} \\ & \mathrm{R} \\ 9 & \mathrm{R} \\ 10 & \mathrm{R}\end{array}$

$\begin{gathered}\text { O week } \\ \mathrm{R}\end{gathered}$
$\mathrm{R}$
$\mathrm{Neg}$
$\mathrm{R}$
$\mathrm{R}$

lst week
$R$
$502 \mathrm{~A}$
$\mathrm{R}+$
$\mathrm{R}$
$\mathrm{R}$
$\mathrm{Neg}$
$502 \mathrm{~A}$
$502 \mathrm{~A}$
$502 \mathrm{~A}$
$502 \mathrm{~A}$
$\mathrm{R}+$
$502 \mathrm{~A}$
$502 \mathrm{~A}$

3rd week
$502 \mathrm{~A}$
$\mathrm{R}$
$\mathrm{R}$
$\mathrm{R}$
$\mathrm{R}$
$502 \mathrm{~A}$
$502 \mathrm{~A}$
$502 \mathrm{~A}$
$502 \mathrm{~A}$
$\mathrm{R}+$
$502 \mathrm{~A}$
$\mathrm{R}+$
$502 \mathrm{~A}$
5 th week 7 th week $502 \mathrm{~A} \quad 502 \mathrm{~A}$ $\mathrm{R}-\mathrm{R}$

Lyosostaphin pretreatment prior to 502A colonization. All subjects were heavy $S$, aureus nasal carriers. The control (C) subjects received a placebo vehicle and the treatment group $(\mathrm{Rx})$ lysostaphin lotion. All were colonized with $502 \mathrm{~A}$ on days 13 through 18 . Note that the resident strain $(R)$ was replaced by strain $502 \mathrm{~A}$ in 3 of 6 volunteers in the lysostaphin group.

As seen in Table III, this local treatment did allow subsequent colonization with strain $502 \mathrm{~A}$ in 3 of 6 treated subjects. This clearly is not a panacea. Other approaches are indicated. We believe that a logical approach to this requires a clear understanding of nasal ecology. Even this is a gross simplification for not only do the nares carry $S$. aureus, but also other body sites. 


\section{PRESENT APPROACH}

We believe on the basis of the above that the principle of bacterial interference with strain 502A represents a valuable therapeutic tool for the patient severely plagued with recurrent furunculosis. Even though relative safety has been documented, we do not use it except in individuals with an arbitrary minimum of 1 year of frequent infections. In our laboratory we do an extensive workup for each patient.

In the clinical situation, we believe the following regimen practical and realistic. After appropriate history and physical examination to rule out underlying disease, the patient's nose and throat are cultured. The coagulase-positive staphylococci should be phage typed in a reference laboratory. The antibiotiogram is also helpful in identifying that the strain is different from $502 \mathrm{~A}$. If such an organism is demonstrated either with bacteriophage typing or an antibiotiogram, the risks and benefits are explained to the patient.

We place the patient on full therapeutic doses of an appropriate oral antibiotic (usually a semisynthetic penicillin) for a minimum of 5 days or preferably until cultures are negative. If there is history of skin disease or a clustering of boils on any part of the body, we culture those sites. The perineum has been a major source of carriage in several of our patients.

A topical antibiotic is used as well. We prescribe a semisynthetic penicillin ointment or a neomycin/polymixin/bacitracin combination. This is liberally applied several times daily to the anterior nares and to the other carriage sites such as the perineum.

After antibiotic treatment, the patient is colonized with $502 \mathrm{~A}$. Although more quantitative methods could be utilized, we find it sufficient to place one drop of an overnight culture (prepared from a lyophilized culture) rubbed into each nostril daily for 5 consecutive days. To ascertain if colonization is successful, we request the patient to return in 1 month for a nasal culture, for an antibiotiogram and/or phage typing. If the colonization is not successful, we repeat the procedure.

\section{MECHANISMS OF ACTION}

The principle of bacterial interference will probably find wider use than just in the treatment of the relatively uncommon recurrent furunculosis. We believe it may have a future in many areas of infectious disease and in burn therapy (Anthony and Wannamaker, 1967). Much work needs to be done before the goals can be realized. Nevertheless, it appears appropriate to briefly review the information on mechanisms of action.

Colonization requires live organisms. Attempts to induce colonization with killed organisms have been unsuccessful - at least in burns (Anthony and Wannamaker, 1967). Interference appears to be site specific. However, it is not species specific. In certain instances, at least-in vitro-interference can occur with organisms other than S. aureus.

There does not seem to be a lasting immunity. In other words, if the interfering strain is lost, there is no further protection. Protection appears to be independent of humoral antibody. Individuals with large amounts of antibody have no more protection than individuals with modest amounts. Lastly, in vitro data in an embryonic egg system suggest that an inhibitor is involved and it is not just the exhaustion of a nutrient (Ribble and Shinefield, 1967).

This study was supported in part by NASA Contract No. NGR 05-025-008. Sally Ronquillo and Kitty Phelps provided expert technical assistance. We acknowledge with gratitude the cooperation of Drs. Lester Pope and Eugene Prout of the California State Department of Corrections.

\section{REFERENCES}

ANThoNY, B. and Wannamaker, L. (1967) Bacterial Interference in Experimental Burns. J. exp. Med., 125,319 .

Boris, M. (1968) Bacterial Interference: Protection against Staphylococcal Disease. Bull. NY. Acad. Med. (second series). 44, 1212. 
Boris, M., Shinffield, H., Romano, P., McCarthy, D and Florman, A. (1968) Bacterial Interfer. ence, Protection Against Recurrent Intrafamilial Staphylococcal Disease. Am. J. Dis. Child., 115, 521 .

Drutz, D., VAN WAY, M., Schaffner, W. and Koenia, M. (1966) Bacterial Interference in the Therapy of Recurrent Staphylococcal Infections. New Engl. J. Med., 275, 1161.

Marbach, H. I. (1962) Staphylococcus Toxoid. In Symposium on Bacterial Infections of the Skin, Proc. XII Internat. Congress Derm. Washington. p. 1035.

Martin, R. and White, A. (1967) The Selective Action of Lyostaphin in Vitro, J. Lab. clin. Med., 70, 1. Ribble, J. and Shinefield, H. (1967) Bacterial Interference in Chick Embryos. J. clin. Invest., 46,446 .

Roodyn, L. (1960) Epidemiology of Staphylococcal Infections. J. Hyg., 58, 1.

Shinefield, H., RibBle, J., Eichenwald, H., Boris, M. and Sutherland, J. (1966) Bacterial Interference, Chapter 17. In Skin Bacteria and Their Role in Infection. Edit. Maibach, $\mathrm{H}$. and Hildick-Smith, G., New York, McGraw Hill.

Strauss, W., Marbach, H. and Hurst, V. (1965) Purposeful Change of Staphylococcal Bacteriophage Types. J. Am. med. Ass., 191, 759 . 